\title{
Effect of simulated dawn on quality of sleep - a community-based
} trial

\author{
Sami Leppämäki*1,2, Ybe Meesters ${ }^{3}$, Jari Haukka ${ }^{1}$, Jouko Lönnqvist ${ }^{1}$ and \\ Timo Partonen ${ }^{1}$
}

Address: ${ }^{1}$ Department of Mental Health and Alcohol Research, National Public Health Institute, Helsinki, Finland, ${ }^{2}$ Department of Psychiatry, Helsinki University Central Hospital, Jorvi Hospital, Espoo, Finland and ${ }^{3}$ Department of Biological Psychiatry, Academic Hospital Groningen, Groningen, The Netherlands

Email: Sami Leppämäki* - sami.leppamaki@ktl.fi; Ybe Meesters - y.meesters@acggn.azg.nl; Jari Haukka - jari.haukka@ktl.fi; Jouko Lönnqvist - jouko.lonnqvist@ktl.fi; Timo Partonen - timo.partonen@ktl.fi

* Corresponding author

Published: 27 October 2003

BMC Psychiatry 2003, 3:14
Received: 21 January 2003

Accepted: 27 October 2003

This article is available from: http://www.biomedcentral.com/I47I-244X/3/14

(C) 2003 Leppämäki et al; licensee BioMed Central Ltd. This is an Open Access article: verbatim copying and redistribution of this article are permitted in all media for any purpose, provided this notice is preserved along with the article's original URL.

\begin{abstract}
Background: Morning light exposure administered as simulated dawn looks a promising method to treat Seasonal Affective Disorder, but it may moreover help with resetting the inaccurate organisation of body clock functions relative to sleep occurring in winter among people in general. Disturbances in sleep patterns are common and may compromise wellbeing even in the short term. Our hypothesis was that simulated dawn could improve the subjective quality of sleep during winter.
\end{abstract}

Methods: A community-based trial with 100 volunteer subjects provided with dawn simulators. Study period lasted for eight weeks, and subjects used the dawn simulators for two weeks at a time, each subject acting as his own control (ABAB-design). Main outcome measure was subjective quality of sleep recorded each morning with Groningen Sleep Quality Scale.

Results: 77 subjects completed the trial. Quality of sleep improved while subjects were using dawn simulator-devices $(p=0.001)$. The treatment became beneficial after six days' use of dawn simulator, but the effect did not last after the use was ceased.

Conclusion: Dawn simulation may help to improve the subjective quality of sleep, but the benefits are modest. Further research is needed to verify these findings and to elucidate the mechanism by which dawn simulation acts on the sleep-wake pattern.

\section{Background}

Intrinsic biological rhythms allow living organisms to anticipate and adapt to environmental changes. They are generated by inherited time-keeping mechanisms and entrained by signals from the individual's natural habitat to match the solar day [1] and transitions between diurnal and nocturnal states [2].
Light is the most important Zeitgeber, or time-giver in humans. During winter it is thus possible that the biological clockwork becomes less stable due to lower light intensity and shorter photoperiod. We hypothesised that to a number of people simulated dawn $[3,4]$ would be of some help during winter in particular. It might keep the endogenous clock in a desired phase position relative to 
standard clock time, preventing desynchronization, facilitating sleep and improving the process of waking up.

Seasonal Affective Disorder (SAD) is a form of recurring affective disorder, in which a depressive episode usually begins in autumn/winter and remission follows in spring/ summer (winter-SAD). Bright light (over 2500 lux) is considered the treatment of choice in winter-SAD, and more effective than dawn simulation [5]. In a recently published controlled trial Avery et al. found that dawn simulation was superior to placebo in alleviating symptoms of SAD [6]. In an earlier report, a slower light ramp (increasing illuminance over $45 \mathrm{~min}$, peaking at $100 \mathrm{lux}$ ) was better than rapidly increasing illuminance $(4 \mathrm{~s}$, peaking at 100 lux) in improving mood and quality of sleep in subjects with subsyndromal-SAD [7].

Dawn-dusk simulation has been successfully used to treat disturbed circadian rest-activity cycles in patients with dementia [8]. We present, to our knowledge, the first study on the effect of dawn simulation on sleep on a nonclinical population.

\section{Methods}

A random sample, comprising of 1000 subjects aged over 17 years, with 1:1 sex ratio, was drawn from the national population register of Finland. These one thousand subjects were sent a letter inviting them to take part in a trial focusing on the effects of dawn simulation on sleep. The study procedure was briefly described in the invitation letter. No reference to sleeping problems and/or seasonal changes in mood was made in the recruitment letter. Subjects who were not shift workers and who had not been hospitalised nor taking medication during the previous six months were eligible for the study. The first 100 eligible respondents to the invitation letter were enrolled in the trial, after giving their written informed consent. This trial was part of a larger, binational study whose report is currently under preparation [9].

The study protocol is in concordance with the Helsinki declaration and its amendments, and it was approved by the local ethics committee.

The dawn simulators used were 'Light wake-up system' prototypes (Philips DAP), in which the light source was placed behind a diffuser. Research assistant provided the study subjects with the dawn simulator and visited each subject's bedroom to ensure the correct usage of the apparatus. The assistant checked 1) that the bedrooms could be darkened ( $<1$ lux), 2) that the dawn simulator could be placed on a bedside table, or equivalent, on the subject's side of the bed, at eye level, 3 ) that the distance to subject's eyes (approximately $30 \mathrm{~cm}$ ) and illuminance were same in all bedrooms. There were no bed partners in the study subjects. With the dawn simulator the luminance is weak ( $<1$ lux) initially but intensifies following a linear ramp, reaching highest level in 30 minutes. After that, the lamp could be switched off. The trial was preceded by two days of adaptation during which subjects were instructed to use the dawn simulator and adjust the maximum level of illuminance. They were asked to set it at $200 \mathrm{~lx}$ for the first morning, but allowed to change it to either 100 or $300 \mathrm{~lx}$ for the second. Finally, they were asked to stick to the preferred level and use it daily throughout the trial. The dawn simulator was thus to function as their alarm clock on workdays, and they were also instructed to use it in the same way, and set for the same time, at weekends. The trial lasted eight weeks: two weeks of simulated dawn were followed by two weeks without, and this cycle was then repeated once. Half of the subjects followed the opposite design, starting without simulated dawn. Subjects were instructed to contact the research assistant if they had problems with the dawn simulator. The assistant collected the study questionnaires and dawn simulators at the end of each study period.

During the study period all subjects lived in the Helsinki region or South Finland province $\left(60^{\circ}-61^{\circ} \mathrm{N}\right)$. The study was performed in two periods (time of sunrise-sunset): 4 October (7:33am-6:43pm) to 29 November (8:53am$3: 24 \mathrm{pm})$, and 10 January (9:16am-3:40pm) to 7 March (7:02am-6:02pm).

The main outcome measure was quality of sleep, assessed daily using the 14-item Groningen Sleep Quality Scale (GSQS; see Appendix 1 for the items on the scale) [10]. GSQS score ranges from 0 to 14 , a higher score indicating lower subjective quality of sleep. The scale was originally constructed to study sleeping problems of depressed patients. In a validation study with 80 depressed inpatients, the mean (S.D.) score on the scale was 6.0 (4.2) and Cronbach's alpha for internal consistency 0.88 [Mulder-Hajonides van der Meulen \& van den Hoofdakker, unpublished data]. The GSQS has previously been used in a study 27 SAD patients [11], and 70 shiftworkers [12]. In general, if sleep is unrestricted and undisturbed, subjects score 0 to 2 points. A higher score ( 6 to 7 ) indicates a disturbed sleep.

At baseline, the subjects filled in the Seasonal Pattern Assessment Questionnaire (SPAQ; [13]), and the Morningness-Eveningness Questionnaire (M-EQ; [14]. The SPAQ measures seasonal changes in mood and behaviour and includes a 6-item scale yielding the Global Seasonality Score (GSS), ranging from 0 to 24 points. The SPAQ criteria for subsyndromal SAD used in this study were those described by Bartko \& Kasper [15]. The M-EQ has 19 items, which are scored from a minimum of 16 points to a maximum score of 86 points. The scale is divided into 
Table I: Mean (S.D) values on the GSQS after the first and last night of each study period and average score for each two-week period

\begin{tabular}{|c|c|c|c|c|c|c|c|c|c|c|c|c|}
\hline & \multicolumn{12}{|c|}{ STUDY PERIOD (PERIODS WITH DAWN SIMULATION MARKED) } \\
\hline & & I & & & II & & & III & & & IV & \\
\hline & FIRST & LAST & AVERAGE & FIRST & LAST & AVERAGE & FIRST & LAST & AVERAGE & FIRST & LAST & AVERAGE \\
\hline $\begin{array}{l}\text { GROUP I } \\
(N=23)^{\dagger}\end{array}$ & 4.4 (4.4) & $\underline{3.4(5.0)}$ & $\underline{3.8(2.9)}$ & $3.0(5.0)$ & $2.4(4.1)$ & $3.2(2.0)$ & $\underline{2.3(3.3)}$ & $3.3(5.3)$ & $\underline{2.9(2.0)}$ & $3.4(3.5)$ & $4.8(5.1)$ & $4.2(3.3)$ \\
\hline $\begin{array}{l}\text { GROUP } 2 \\
(N=23)^{\dagger}\end{array}$ & $4.7(3.6)$ & $2.7(3.1)$ & $3.7(1.8)$ & $\underline{2.5(3.9)}$ & $\underline{2.1(2.3)}$ & $3.0(1.7)$ & $3.2(3.1)$ & $1.7(3.4)$ & $2.7(1.4)$ & $5.7(3.7)$ & $\underline{1.1(1.8)}$ & $\underline{2.9(1.0)}$ \\
\hline $\begin{array}{l}\text { GROUP } 3 \\
(N=20)^{\ddagger}\end{array}$ & $5.7(4.8)$ & $4.8(5.2)$ & $3.9(2.8)$ & $2.6(4.2)$ & $3.2(4.8)$ & $2.8(1.8)$ & 3.4 (3.8) & $\underline{2.6(4.2)}$ & $\underline{2.4}(1.6)$ & $4.7(4.4)$ & $2.4(4.5)$ & $2.7(2.1)$ \\
\hline $\begin{array}{l}\text { GROUP } 4 \\
(N=25)^{\ddagger}\end{array}$ & $5.4(4.4)$ & $5.0(4.5)$ & $5.0(3.4)$ & $\underline{2.0(3.2)}$ & $3.8(4.4)$ & $3.0(1.8)$ & $4.0(4.0)$ & $2.6(3.6)$ & $3.5(1.9)$ & $3.5(3.7)$ & $1.9(4.6)$ & $\underline{2.8(1.4)}$ \\
\hline
\end{tabular}

† AUTUMN GROUP (OCTOBER TO NOVEMBER) ‡ WINTER GROUP (JANUARY TO MARCH)

five types: definitely / moderately morning type, intermediate type, and definitely / moderately evening type. In this study, a tripartite division was used: evening type (MEQ score 16 to 31 ), neither type (42 to 58 ), or morning type (59 to 86 ).

Before the study, subjects were asked about their expectations on dawn simulation, and how do they think it is going to make them feel. The question was rated on a seven-point scale from "really worse" to "really better".

After the study, the participants were asked to rate how they felt the intervention had affected their general wellbeing on a five-point scale from "worse" to "better". Any possible side effects were also asked after the study from those who completed the trial.

Data were screened and analysed with the S-Plus 2000 Professional for Windows Release 1 (Mathsoft, Inc.). To estimate the intervention effect on the GSQS, a linear mixed-effects model (LME) for longitudinal data was used [16]. The absolute value of the GSQS was set as the dependent variable, and treatment effect, treatment $\times$ time interaction, and baseline characteristics as independent fixed effects. The LME accounts for intra-individual variation in a repeated measures design by setting the variation as a random effect and treating each individual as a cluster in modelling. To test whether the treatment effect lasted after each intervention, a carry-over indicator was included in the model.

\section{Results}

Of the 100 subjects recruited, 94 entered the study. We received some sleep quality-data from 91 subjects ( $97 \%)$. These data are presented in Table 1. Complete data were received from 77 (82\%) subjects, which were included in the statistical analysis. These subjects were 47 women and 30 men, aged on average 35.3 years (range 18 to 70 ). Their mean (S.D.) total GSS was 9.4 (4.3). Twenty-six of them $(33.8 \%)$ had a GSS of 12 points or higher. On basis of SPAQ, 21 subjects $(27.3 \%)$ were classified as having at least subsyndromal-SAD. Seven subjects (9.1\%) classified themselves as morning types on the M-EQ and 16 $(20.8 \%)$ as evening types, the majority $(70.1 \%)$ being neither type. The average illuminance from the dawn simulators, chosen by the participants, was 214 lux.

Four subjects dropped out from the study because they travelled abroad during the study periods. Four subjects reported that they, or their children, had fallen ill during the study, and they were unable to complete the questionnaires. Two subjects reported that their dawn simulator did not work properly. One subject reported that the light made her nervous. Other subjects $(n=6)$ who dropped out from the study did not give any particular reason.

Of those who completed the study, 35\% reported the dawn simulation had made them feel better or a bit better. 9.2\% reported they had experienced side effects attributed to the light.

In the statistical analysis treatment $\times$ time interaction was highly significant $(\mathrm{p}=0.001)$. The quality of sleep improved constantly ( 0.19 units per day) during the daily administration of simulated dawn. It took six days for the treatment benefit to appear, and after two weeks, the mean improvement was 1.7 points. The level of light intensity, age (both as a continuous variable and with a cut-off point; 40 years or older), sex, season (autumn/winter), seasonality (GSS as a continuous variable and subsyndromal SAD; yes / no), morningness-eveningness, and pre-intervention expectations were accounted for, and did not influence the outcome. The carry-over indicator was not significant. Table 2 presents the key results of the LME-model.

\section{Discussion}

Sleep problems are common: in a nation-wide survey in America, one individual in three reported having occasional difficulty sleeping, and nearly 10\% complained of sleep problems occurring on a regular, nightly basis [17]. Disorders of sleep tend to increase with age [18]. Our 
Table 2: Effect of simulated dawn and baseline characteristics on the quality of sleep scale.

\begin{tabular}{|c|c|c|c|}
\hline & Value & $95 \% \mathrm{Cl}$ & $\mathrm{P}$-value \\
\hline Treatment effect & 0.94 & -0.14 to 2.07 & 0.1 \\
\hline Treatment $\times$ time effect ${ }^{1}$ & -0.19 & -0.30 to -0.07 & 0.001 \\
\hline Pre-intervention expectations & -0.58 & -1.50 to 0.35 & 0.2 \\
\hline $\mathrm{Age}^{2}$ & 0.005 & -0.02 to 0.03 & 0.7 \\
\hline Seasonality ${ }^{3}$ & 0.28 & -0.03 to 0.60 & 0.08 \\
\hline M-EQ - morningness & -0.28 & -0.87 to 0.31 & 0.4 \\
\hline M-EQ - eveningness & 0.03 & -0.25 to 0.31 & 0.8 \\
\hline Time of year (autumn/winter) & -0.07 & -0.34 to 0.20 & 0.6 \\
\hline
\end{tabular}

I The effect of treatment and time interaction on a linear scale ${ }^{2}$ As a continuous variable ${ }^{3}$ Sub-syndromal SAD, yes vs. no

results suggest that simulated dawn improves subjective quality of sleep during the dark months in autumn and winter. It appears effective in relatively healthy males and females regardless of age.

Simulated dawn has been shown to prevent the phase delay naturally occurring in the human circadian pacemaker [19]. In addition, even one simulated dawn is sufficient to phase advance the timing of the onset of melatonin secretion [20]. This phase advance might be one mechanism explaining the observed benefits on sleep. However, we didn't measure melatonin levels in this field study, so the hypothesis can't be confirmed. Also, contrary to the phase delay hypothesis, subjects with possible (subsyndromal)-SAD and those regarding themselves as "night owls" on the M-EQ, did not benefit from the intervention more than others. Timing of the light stimuli relative to circadian phase was not controlled in this study; the subjects were asked to keep their sleepwake rhythms constant, but they were free to choose the wake-up time. This naturally limits the interpretation of the results.

Another shortcoming of the study is admittedly its design: we did not have a placebo condition, and the subjects were acting as their controls. Lack of creditable placebo is common in trials with bright light [21]. Also, selection must have occurred in the invitation phase: it is more probable that subjects regarding dawn simulation favourably participated. We did, however, measure the pre-intervention expectations, and they were not found to influence the results.

The Groningen Sleep Quality Scale seems a promising and reliable method of measuring sleep quality even in the general population. In future it should, however, be validated against more established questionnaires, e.g. The Pittsburgh Sleep Quality Index [22].

\section{Conclusion}

Simulated dawn appears to be a safe, relatively well-tolerated, and possibly effective means of alleviating sleep disturbances related to the shorter photoperiod during winter. However, the improvement on quality of sleep was modest, and we could not identify a specific subgroup who would especially benefit from this intervention.

\section{Competing interests}

None declared.

\section{Authors' contributions}

SL analyzed the data and wrote the final manuscript, TP and YM participated in the planning and co-ordinating of the study and co-authored the manuscript. JH planned the statistical analysis and analyzed the data. JL contributed to planning and supervising the study. All authors have read and approved the final manuscript.

\section{Appendix - The Groningen Sleep Quality Scale} 1. I had a deep sleep last night

2. I feel that I slept poorly last night

3. It took me more than half an hour to fall asleep last night

4. I woke up several times last night

5. I felt tired after waking up this morning

6. I feel that I didn't get enough sleep last night

7. I got up in the middle of the night

8. I felt rested after waking up this morning

9. I feel that I only had a couple of hours' sleep last night 
10. I feel that I slept well last night

$$
\text { 11. I didn't sleep a wink last night }
$$

12. I didn't have trouble falling asleep last night

13. After I woke up last night, I had trouble falling asleep again

14. I tossed and turned all night last night

15. I didn't get more than 5 hours' sleep last night

All items are scored true / false

The first question does not count for the total score

One point if answer is 'true': questions 2, 3, 4, 5, 6, 7, 9, $11,13,14,15$

One point if answer is 'false': questions 8, 10, 12

Maximum score 14 points, indicating poor sleep the night before

\section{Acknowledgements}

We thank Dr D Beersma for intellectual support, Ms M Havula-Eklund for technical assistance, and Dr E Pulkkinen for help with data processing. This study was partly supported by an unconditional grant from Philips DAP, which also manufactured the devices for research use. SL has received grants from The Finnish Psychiatric Research Foundation and The Signe and Ane Gyllenberg foundation to support his work.

\section{References}

I. Czeisler CA, Duffy JF, Shanahan TL, Brown EN, Mitchell JF, Rimmer DW, JM Ronda, Silva EJ, Allan JS and Emens JS et al: Stability, precision, and near-24-hour period of the human circadian pacemaker. Science 1999, 284:2177-2181.

2. Wehr TA, Aeschbach D and Duncan WC Jr: Evidence for a biological dawn and dusk in the human circadian timing system. J Physiol 200I, 535:937-95I.

3. Terman M, Schlager D, Fairhurst $S$ and Perlman B: Dawn and dusk simulation as a therapeutic intervention. Biol Psychiatry 1989, 25:966-970.

4. Eagles JM: SAD-help arrives with the dawn? Lancet 200I, 358:2100

5. Lingiaerde $O$, Foreland $A R$ and Dankertsen J: Dawn simulation vs. lightbox treatment in winter depression: a comparative study. Acta Psychiatr Scand 1998, 98:73-80.

6. Avery DH, Eder DN, Bolte MA, Hellekson CJ, Dunner DL, Vitiello $M V$ and Prinz PN: Dawn simulation and bright light in the treatment of SAD: a controlled study. Biol Psychiatry 200I, 50:205-216.

7. Norden $\mathrm{MJ}$ and Avery $\mathrm{DH}$ : A controlled study of dawn simulation in subsyndromal winter depression. Acta Psychiatr Scand 1993, 88:67-7|.

8. Gasio PF, Kräuchi K, Cajochen C, van Someren E, Amrhein I, Pache M, Savaskan E and Wirz-Justice A: Dawn-dusk simulation light therapy of disturbed circadian rest-activity cycles in demented elderly. Exp Gerontol 2003, 38:207-2 I6.

9. Meesters $Y$, Beersma DGM and Partonen TT. Dawn simulation for easy wake-up. Soc Light Treatment Biol Rhythms Abstr 1999, I I:32.

10. Mulder-Hajonides van der Meulen WREH, Wijnberg JR, Hollander J, De Diana IPF and van den Hoofdakker RH: Measurement of subjective sleep quality. Eur Sleep Res Soc Abstr 1980, 5:98.
II. Meesters Y, Jansen JHC, Lambers PA, Bouhuys AL, Beersma DGM and van den Hoofdakker $\mathrm{RH}$ : Morning and evening light treatment of seasonal affective disorder: response, relapse and prediction. J Aff Disord 1993, 28:165-I77.

12. Meijman TF, Thunnissen MJ and de Vries-Griever AGH: The aftereffects of a prolonged period of day-sleep on subjective sleep quality. Work Stress 1990, 4:65-70.

13. Rosenthal NE, Genhart MJ, Sack DA, Skwerer RG and Wehr TA: Seasonal affective disorder and its relevance for the understanding and treatment of bulimia. In: The Psychobiology of Bulimia Edited by: Hudson Jl, Pope HG. Washington, DC, American Psychiatric Press; 1987:205-228.

14. Horne JA and Östberg O: A self-assessment questionnaire to determine morningness-eveningness in human circadian rhythms. Int J Chronobiol 1976, 4:97-II0.

15. Bartko J and Kasper S: Seasonal changes in mood and behavior: a cluster analytic approach. Psychiatry Res 1989, 28:227-239.

16. Laird NM and Ware $\mathrm{JH}$ : Random-effects models for longitudinal data. Biometrics 1982, 38:963-974.

17. Ancoli-Israel $\mathrm{S}$ and Roth $\mathrm{T}$ : Characteristics of insomnia in the United States: results of the I 99 I National Sleep Foundation Survey. I. Sleep 1999, 22(suppl 2):S347-S353.

18. Phillips B and Ancoli-Israel S: Sleep disorders in the elderly. Sleep Med 200I, 2:99-II4.

19. Danilenko KV, Wirz-Justice A, Krauchi K, Weber JM and Terman M: The human circadian pacemaker can see by the dawn's early light. J Biol Rhythms 2000, I 5:437-446.

20. Danilenko KV, Wirz-Justice A, Krauchi K, Cajochen C, Weber JM, Fairhurst $S$ and Terman $M$ : Phase advance after one or three simulated dawns in humans. Chronobiol Int 2000, I 7:659-668.

21. Eastman Cl: Is bright-light therapy a placebo? In: Seasonal Affective Disorder. Practice and Research Edited by: Partonen T, Magnusson A. Oxford, Oxford University Press; 2001:103-II2.

22. Buysse DJ, Reynold CF 3rd, Monk TH, Berman SR and Kupfer DJ: The Pittsburgh Sleep Quality Index: a new instrument for psychiatric practice and research. Psychiatry Res 1989, 28:193-213

\section{Pre-publication history}

The pre-publication history for this paper can be accessed here:

http://www.biomedcentral.com/1471-244X/3/14/pre pub

Publish with Biomed Central and every scientist can read your work free of charge

"BioMed Central will be the most significant development for disseminating the results of biomedical research in our lifetime. "

Sir Paul Nurse, Cancer Research UK

Your research papers will be:

- available free of charge to the entire biomedical community

- peer reviewed and published immediately upon acceptance

- cited in PubMed and archived on PubMed Central

- yours - you keep the copyright

Submit your manuscript here:

http://www.biomedcentral.com/info/publishing_adv.asp
BioMedcentral 